\title{
The Use of Opioids and Antipsychotics in Elderly with Dementia - Have Opioids Replaced Antipsychotics in Treating Behavioral Symptoms in Dementia?
}

\author{
Christina Jensen-Dahm ${ }^{\mathrm{a}, *}$, Ane Nørgaard Christensen ${ }^{\mathrm{a}}$, Christiane Gasse ${ }^{\mathrm{b}, \mathrm{c}}$ \\ and Gunhild Waldemar ${ }^{\mathrm{a}}$ \\ ${ }^{a}$ Department of Neurology, Danish Dementia Research Centre (DDRC), Rigshospitalet - University \\ of Copenhagen, Copenhagen, Denmark \\ ${ }^{\mathrm{b}}$ Depression and Anxiety/Psychosis Research Unit, Aarhus University Hospital Psychiatry, \\ Aarhus N, Denmark \\ ${ }^{\mathrm{c}}$ National Centre for Register-based Research, Aarhus University, Aarhus, Denmark
}

Handling Associate Editor: Alba Malara

Accepted 21 October 2019

\begin{abstract}
.
Background: Opioids are used with increasing frequency. Elderly with dementia are prescribed opioids more frequent than elderly without. One possible explanation is that opioids may be used not only to treat pain but also behavioral symptoms.

Objective: To test the hypothesis that strong opioid use, especially transdermal formulations, had increased, especially in elderly with dementia, in parallel with a decrease in antipsychotic use.

Methods: Population-based cross-sectional study conducted using nationwide Danish registers with data on Denmark's entire elderly population age $\geq 65$ (2000: $n=802,106 ; 2015: n=1,056,476)$. The registers were used to identify elderly with and without dementia and filled prescriptions for opioids and antipsychotics. Annual prevalence of opioid and antipsychotic use from 2000-2015 was calculated.

Results: Prevalence of opioid use increased by $35 \%$ (24.2 to $32.5 \%$ ) among elderly with dementia and by $13 \%$ among elderly without (14.9 to $16.8 \%$ ) from 2000-2015. The disproportionate increase in opioid use among elderly with dementia was mainly driven by an increase in strong opioids (dementia: 11.7 to $23.1 \%$; without dementia: 5.9 to $7.4 \%$ ). Use of antipsychotics decreased during the same period (dementia: 31.3 to $19.3 \%$; no dementia: 4.5 to $2.7 \%$ ).

Conclusion: From 2000-2015, use of opioids among the elderly increased with a disproportionately higher increase among elderly with dementia. The parallel decrease in the use of antipsychotics may suggest that opioids to some extent have replaced antipsychotics in managing behavioral symptoms, despite safety concerns and lack of evidence for effect of opioids. Future research should focus on potential risks associated with increased opioid use.
\end{abstract}

Keywords: Antipsychotic, behavioral symptoms, dementia, drug use, opioid, pain

\footnotetext{
${ }^{*}$ Correspondence to: Christina Jensen-Dahm, MD, PhD, The Danish Dementia Research Centre, Department of Neurology, The Neuroscience Centre, Rigshospitalet, University of Copen-
}

hagen, Blegdamsvej 9, \# 6911, 2100 Copenhagen, Denmark. Tel.: +45 28895017; Fax: +45 35452446; E-mail: christina.jensendahm@ regionh.dk. 


\section{INTRODUCTION}

Behavioral symptoms, such as psychosis, aggression, agitation, and wandering, affect nearly all patients with dementia at some point in time [1] and are very distressing [2]. The causes of behavioral symptoms include biological (e.g., underlying pathology, medication side effects, infections, pain), psychological, and environmental factors [3]. Antipsychotics are often prescribed to treat behavioral symptoms but have been associated with serious adverse events and increased mortality, particularly in elderly with dementia [4, 5], leading to safety warnings and regulations worldwide [6-8]. Thus, the focus on appropriate management of behavioral symptoms has increased, with screening for physical and environmental causes prior to initiation of antipsychotics. One hypothesis is that untreated pain can lead to behavioral symptoms and it has been suggested that analgesics (opioids or paracetamol) may also be used to treat the symptoms [9]. However, opioids may be associated with severe side effects [10-12] and should be used with caution. Thus, replacing antipsychotics by opioids would be very problematic in cases where practitioners do not make a thorough workup to identify the cause of behavioral symptoms.

In a recent register-based study of the entire elderly Danish population, we reported that opioids were used more frequently by elderly with dementia [13], but the reason was unknown. Prior research has investigated if a standardized stepwise protocol of analgesics to treat agitation in nursing home residents with moderate to severe dementia [9]. One possible explanation for the frequent use of opioids could be that opioids were used to treat behavioral symptoms in general in elderly with dementia and not only when thought to be caused by pain. One way of examining this further is to investigate prescription practices and examine changes in use of opioids and antipsychotics over time. Danish registries are unique with respect to capturing an entire population, disclosing important information about prescription practices relevant in an international context. Thus, we aimed to investigate changes in use of opioids and antipsychotics in elderly with and without dementia in Denmark from 2000-2015. Our previous study found that strong opioids, particularly transdermal formulations (i.e., fentanyl and buprenorphine), were used frequently. We wanted to test the hypothesis that strong opioid use, especially transdermal formulations, had increased, especially in elderly with dementia, in parallel with a decrease in the use of antipsychotics.

\section{METHODS}

\section{Study design}

This population-based cross-sectional study used nationwide Danish registers. We calculated annual prevalence of opioid and antipsychotic use. The study was approved by the Danish Data Protection Agency (ID no.: 2007-58-0015/30-0667), Statistics Denmark, and the Danish Health and Medicines Authority (ID no.: 6-8011-907/1). Danish law does not require ethics committee approval or written informed patient consent for register based studies.

\section{The registers}

In Denmark, all permanent residents are assigned a personal identification number at birth or immigration, making it possible to link demographic and medical data from nationwide registers at an individual level [14]. Denmark has a public healthcare system, where all somatic hospital admissions and visits to outpatient clinics and emergency rooms are registered in the National Patient Registry [15], while psychiatric admissions and outpatient visits are in the Psychiatric Central Registry [16]. Data on all dispensed prescription drugs is registered in the Danish National Prescription Registry according to the Anatomical Therapeutic Chemical (ATC) classification system [17] (for further details, see [13]).

\section{Study population}

The annual population was defined each year on January 1 (from 2000 to 2015) and included all Danish residents age $\geq 65$. Thus, an individual could be included at multiple index dates following their 65th birthday, if still alive. Elderly with dementia were identified as in- and outpatients registered with a dementia diagnosis (see Supplementary Table 1 for diagnostic codes) and/or as individuals who had filled at least one prescription for an anti-dementia drug (ATC: N06D). Individuals diagnosed or prescribed an anti-dementia drug before age 60 were excluded from the population. The remaining elderly population age $\geq 65$ without dementia formed the reference population (for further details, see [18]). Time since diagnosis was applied as a surrogate marker of severity of illness. 


\section{Medication use}

A user of a drug was defined as an individual who had filled at least one prescription within a year. In Denmark, opioids are only available by prescription from a physician and can only be dispensed once per prescription. Opioids (N02A) were grouped as strong opioids (morphine analogues (N02AA01-04), oxycodone (N02AA05-55), pethidine (N02AB02), fentanyl (N02AB03), buprenorphine (N02AE01), and ketobemidone (N02AG02)) and weak opioids ((codeine (N02AA59), dextropropoxyphene (N02AC04), and tramadol (N02AX02)). Only fentanyl (N02AB03) and buprenorphine (N02AE01) are available as transdermal formulations, and these were grouped as such. Antipsychotics (N05A) included both first and second-generation but excluded lithium (N05AN). Annual prevalence of all opioids, strong opioids, weak opioids, transdermal formulations of opioids, and antipsychotic use in elderly with and without dementia was calculated annually according to the population.

To evaluate the amount used in a given year, we calculated equivalent doses of oral morphine and total dose for each user (Supplementary Table 2). The equianalgesic dose of morphine in one defined daily dose (DDD) varies from opioid to opioid (see Supplementary Table 2). The equianalgesic content of one DDD does not reflect a suitable dose for an elderly person, i.e., one DDD of oral morphine is $100 \mathrm{mg}$, which is very high dose for an elderly. To calculate duration of use, equianalgesic doses were calculated and a daily dose equivalent of $30 \mathrm{mg}$ of oral morphine was assumed.

\section{Comorbidity}

Comorbidity was evaluated in the year prior to the index date. Data from somatic and psychiatric hospital contacts was used to identify comorbid conditions. We evaluated potentially pain-causing diseases (cancer, osteoporosis, arthritis recent fracture, and diabetes) and comorbidity (vascular, pulmonary, renal, and liver disease) that may affect opioid use (Supplementary Table 3). The total amount of comorbidity was evaluated using the Charlson Comorbidity Index score, which comprises 19 chronic somatic diseases [19]. Psychiatric comorbidity was defined as a registered diagnosis of prior psychotic disorders (one of the following diagnoses: schizophrenia, schizotypal, delusional disorders (ICD-8:295.x9, 296.89, 297.x9, 298.29-
298.29-298.99, 299.04, 299.05, 299.09, 301.8; ICD-10: F20-29); and, manic episode and bipolar affective disorder (ICD-8:296.19, 296.39, 298.19; ICD-10: F30-F31)) registered any time since 1969 before the dementia diagnosis. The total number of different drugs used in the year prior was employed as a surrogate marker of somatic disease not captured by hospital admissions (ATC level 3).

\section{Statistical analysis}

Comparison of annual prevalence of drug use requires independent observations. To achieve independency between observations, the population was divided into five-year age groups (age 65-69, 70-74, 75-79, 80-84, 85-89, 90-94, 95-99). Drug use in each group was compared between 2000, 2005, 2010, and 2015. Thus, an individual could not be represented at more than one time point in the same age group. The reference year was 2000. A logistic regression analysis was done separately for elderly with and without dementia. A crude logistic regression analysis was performed with calendar year as the independent variable. Age, sex, and individual comorbidity (i.e., cancer, osteoporosis, arthritis, recent fracture, diabetes, vascular, pulmonary, renal, and liver disease) were included in the multivariate logistic regression analysis as potential confounders. A $p$-value of $<0.05$ was considered statistically significant. The data analysis was performed using SAS statistical software, version 9.4 (SAS Institute Inc., Cary, NC, USA).

\section{RESULTS}

\section{Study population}

Figure 1 shows the selection of the population. In 2000 , there were 19,062 elderly age $\geq 65$ with dementia and 781,056 elderly without in Denmark, which increased to 36,114 and $1,017,932$, respectively, in 2015. Table 1 lists the characteristics of the study population. In both 2000 and 2015, elderly with dementia were older, more likely to be female, used more drugs, and suffered from more comorbidity than elderly without.

\section{Opioid use}

\section{Prevalence}

Figure $2 \mathrm{~A}$ and $2 \mathrm{~B}$ present the annual prevalence of use of all opioids. From 2000 to 2015, the preva- 
A

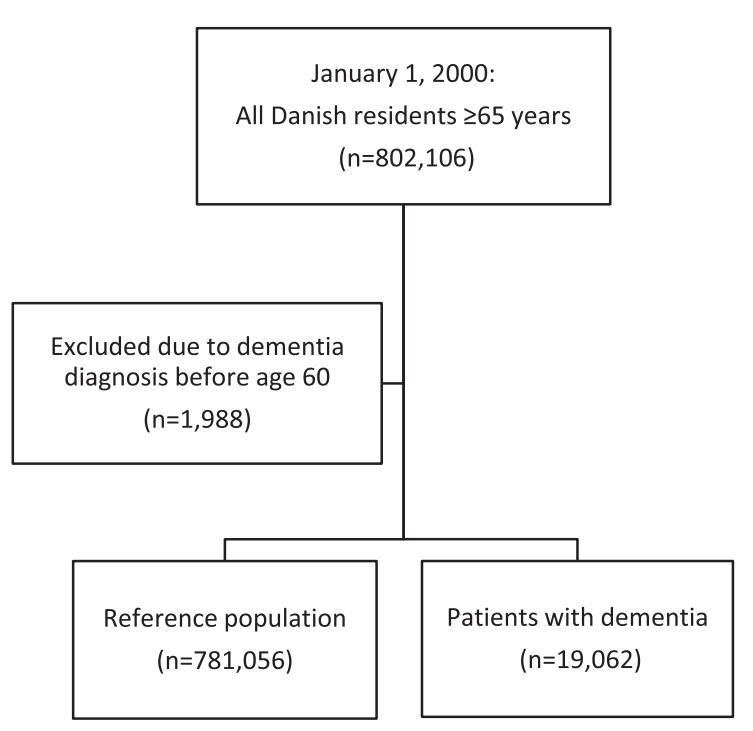

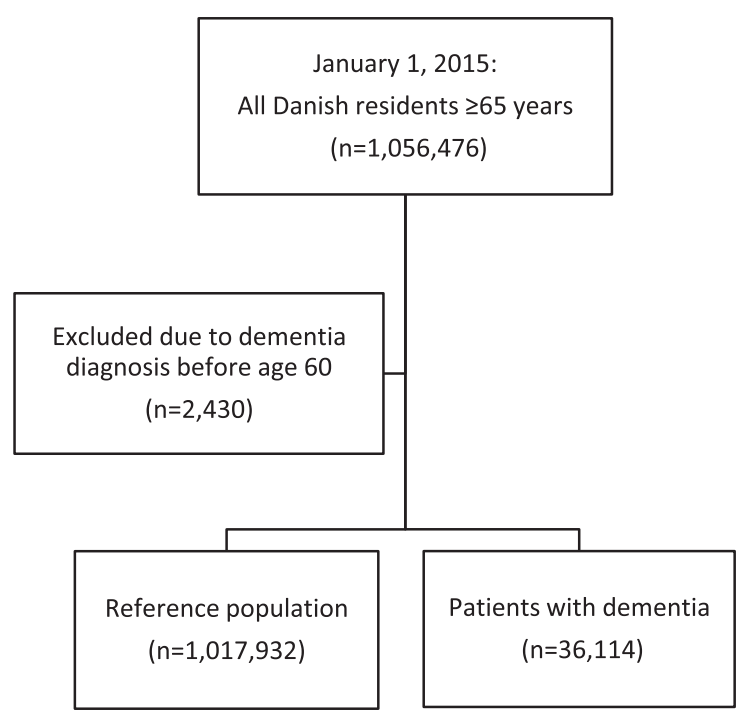

Fig. 1. Study population in 2000 (A) and 2015 (B).

Table 1

Characteristics of the Study Population in 2000 and 2015

\begin{tabular}{lccccc}
\hline \multirow{2}{*}{ Characteristic } & \multicolumn{2}{c}{2000} & & \multicolumn{2}{c}{2015} \\
\cline { 2 - 3 } \cline { 5 - 6 } & $\begin{array}{c}\text { Patients with } \\
\text { Dementia } \\
(n=19,062)\end{array}$ & $\begin{array}{c}\text { Elderly without } \\
\text { Dementia } \\
(n=781,056)\end{array}$ & $\begin{array}{c}\text { Patients with } \\
\text { Dementia } \\
(n=36,114)\end{array}$ & $\begin{array}{c}\text { Elderly without } \\
\text { Dementia } \\
(n=1,017,932)\end{array}$ \\
\hline Age, y & $82.2(77.0-87.1)$ & $74.3(69.4-80.1)$ & $83.2(77.5-88.2)$ & $72.6(68.7-78.8)$ \\
Women & $12,865(67.5 \%)$ & $452,944(58.0 \%)$ & $22,849(63.3 \%)$ & $551,033(54.1 \%)$ \\
Men & $6,197(32.5 \%)$ & $328,112(42.0 \%)$ & $13,265,(36.7 \%)$ & $466,899(45.9 \%)$ \\
Time since diagnosis, y & $2.0(0.9-4.1)$ & - & & $2.9(1.3-5.4)$ & - \\
Prior psychiatric disease & $1,387(7.3 \%)$ & $10,146(1.3 \%)$ & $1,720(4.8 \%)$ & $15,065(1.5 \%)$ \\
Number of drugs used in previous year & $7(4-10)$ & $4(2-7)$ & & $8(6-11)$ & $5(2-8)$. \\
Charlson Comorbidity Index* & $1 *(1-2)$ & $0(0-1)$ & & $2(1-3)$ & $0(0-2)$ \\
Vascular disease & $5,587(29.3 \%)$ & $97,361(12.5 \%)$ & $13,564(37.6 \%)$ & $208,635(20.5 \%)$ \\
Lung disease & $1,418(7.4 \%)$ & $51,883(6.6 \%)$ & & $4,707(13.0 \%)$ & $100,019(9.8 \%)$ \\
Kidney disease & $271(1.4 \%)$ & $8,156(1.0 \%)$ & & $1,708(4.7 \%)$ & $31,354(3.1 \%)$ \\
Liver disease & $206(1.1 \%)$ & $4.607(0.6 \%)$ & & $675(1.9 \%)$ & $12,649(1.2 \%)$ \\
Pain-specific comorbidity & & & & $27,916(2.7 \%)$ \\
$\quad$ Fracture in previous year & $2,037(10.7 \%)$ & $26,258(3.4 \%)$ & $2,896(8.0 \%)$ & $22 \%)$ \\
Osteoporosis & $907(4.8 \%)$ & $17,429(2.2 \%)$ & $6,473(17.9 \%)$ & $106,880(10.5 \%)$ \\
Cancer & $2,113(11.1 \%)$ & $74,411(9.5 \%)$ & $7,396(20.5 \%)$ & $184,819(18.2 \%)$ \\
Diabetes & $1,158(6.1 \%)$ & $21,659(2.8 \%)$ & $4,214(11.7 \%)$ & $78,131(7.7 \%)$ \\
Arthritis & $2,573(13.5 \%)$ & $76,887(9.8 \%)$ & $6,984(19.3 \%)$ & $152,185(15.0 \%)$ \\
\hline
\end{tabular}

*Index calculated without dementia. ${ }^{\dagger}$ Numbers given as $\mathrm{n}(\%)$ and median (25-75\% interquartile range), as appropriate.

lence of opioid use increased by $35 \%$ (24.2 to $32.5 \%$ ) among elderly with dementia. The most noticeable change occurred from 2004 and onwards, with the highest prevalence in 2013 (33.6\%). For elderly without dementia, there was a $13 \%$ (14.9 to $16.8 \%$ ) increase in the prevalence of opioid use from 2000 to 2015, with the highest prevalence in 2010 (17.7\%). Figure 3 presents the results of a logistic regression analysis comparing 2000 versus 2015 in five-year age groups and stratified by dementia (Supplementary Table 4A, B). After adjusting for age, sex, and comorbidity, use of opioids increased in all age groups among elderly with dementia, with the largest increase in 95-99-year-olds (odds ratio (OR) (95\% confidence interval (CI)): 2.05 (1.58-2.67)). In elderly without dementia, there was a slight increase 
A

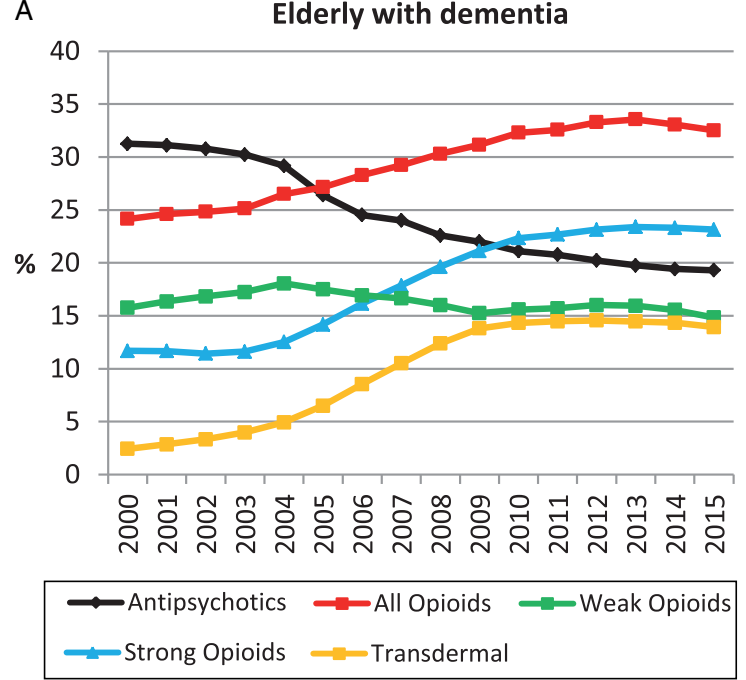

B

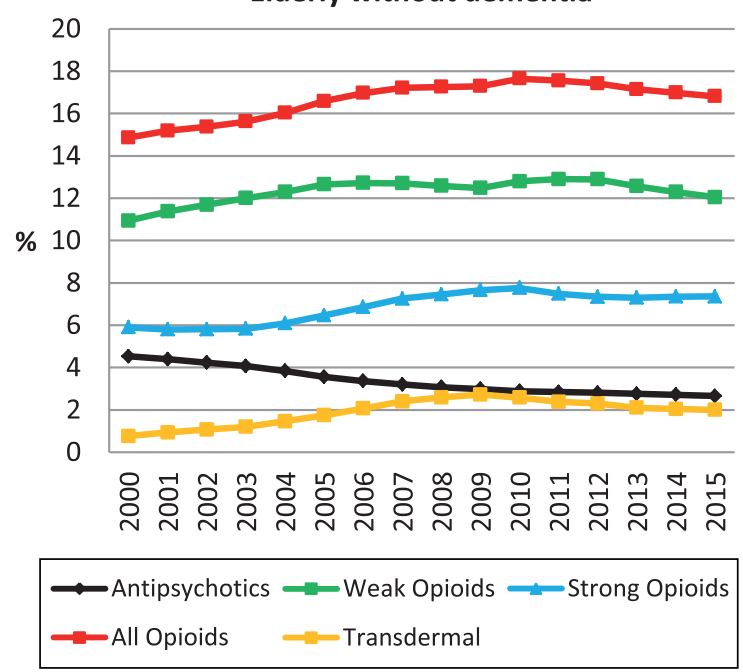

Fig. 2. Prevalence of opioid and antipsychotic use from 2000 to 2015 in elderly with dementia (A) and elderly without dementia (B).

in age >90 (90-94: OR 95\% CI: 1.15 (1.10-1.19); 95-99:1.30 (1.20-1.42)) and a slight decrease or no change in the remaining groups. When comparing CIs, there was a greater increase among elderly with dementia in all age groups compared with elderly without.

\section{Treatment intensity}

Figure 4 shows duration of opioid use. From 2000 to 2015 , the median number of days treated with an opioid increased by $39 \%$ (80 to 111 days) in elderly with dementia but was unchanged for elderly without.
A

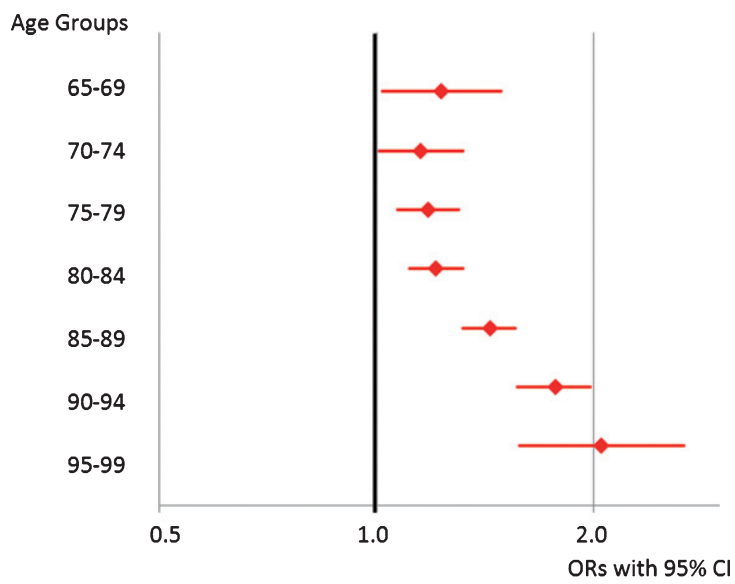

B

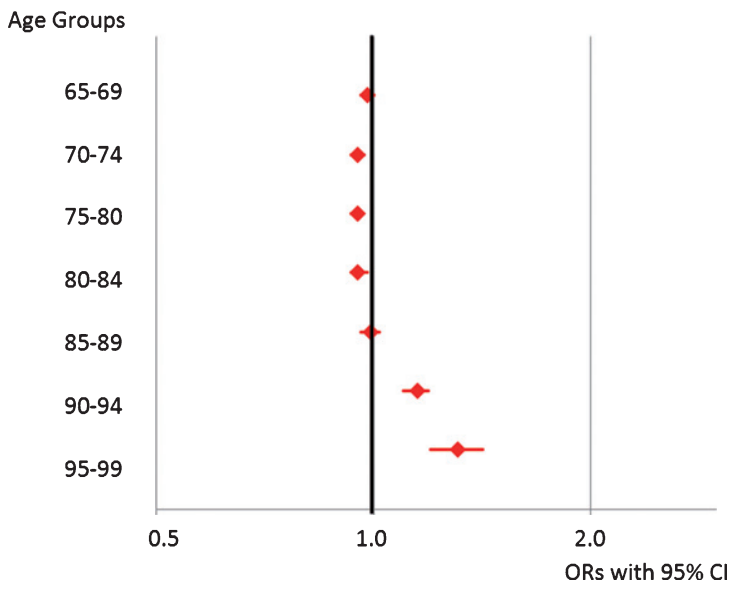

Fig. 3. Changes in Opioid Use in Elderly with Dementia (A) and without Dementia (B). The figure shows the results of logistic regression analyses comparing 2000 versus 2015 in five-year age groups displaying adjusted odds ratios (ORs) and $95 \%$ confidence intervals (CI). The adjusted ORs include adjustment for age, sex, and all comorbidity.

\section{Opioid subtypes}

The increase in prevalence of opioid use in elderly with dementia was mainly driven by an increase in the use of strong opioids, which rose by $98 \%$ (11.7 to $23.1 \%$ ). This increase was caused by a rise in the use of transdermal formulations, which increased by $532 \%$ (2.7 to $14.0 \%)$. The increase in use of strong opioids was lower among elderly without dementia ( $25 \%$ increase; 5.9 to $7.4 \%$ ), while use of transdermal formulations increased by $90 \%$ (1.1 to $2.1 \%$ ).

\section{Antipsychotic use}

Figure 2A and 2B show the annual prevalence of antipsychotic use for elderly with and without demen- 


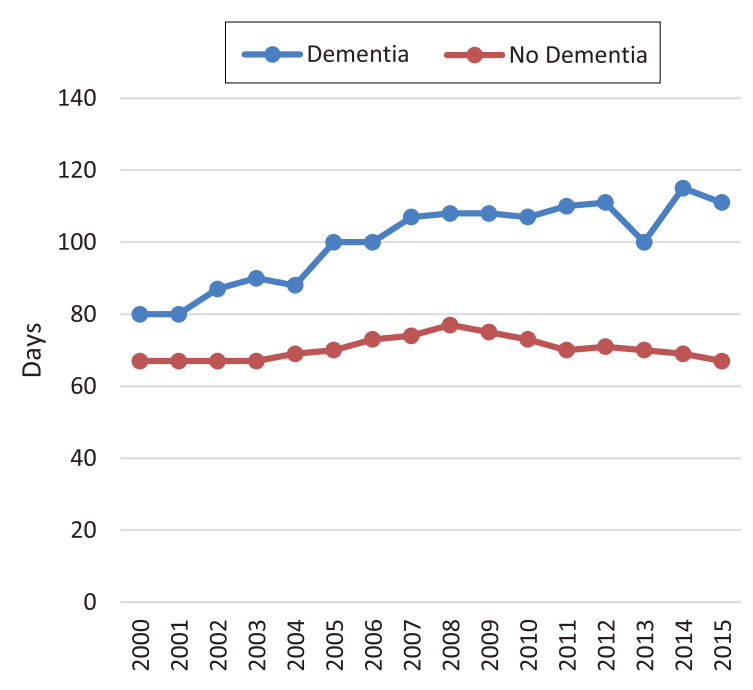

Fig. 4. Opioid treatment intensity. The figure shows the median number of days treated with $30 \mathrm{mg}$ of oral morphine per day in elderly with and without dementia from 2000 to 2015 .

tia (data from 2000 to 2012 previously published) [18]. Antipsychotics decreased by $62 \%$ in elderly with dementia during the period (31.3 to $19.3 \%$ ), with a marked decrease from 2004 and onwards.

\section{DISCUSSION}

The main finding of this study was that the prevalence of opioid use increased significantly from 2000 to 2015. The largest increase in opioid use occurred among elderly with dementia, despite a higher prevalence of opioid use in this group already in 2000. The increase in opioid use in elderly with dementia was mainly due to an increase in strong opioid use. The use of transdermal formulations of opioids, however, increased dramatically in elderly with dementia. During the same period a significant decrease in antipsychotic use was observed in elderly with dementia.

To our knowledge, no previous studies have evaluated changes in opioid prescribing over time in elderly with dementia and then compared the changes with elderly without dementia. Previous studies focused on nursing home residents in general and not on elderly with dementia. A systematic review on studies examining analgesic prescribing among nursing home residents using data collected between 1996 and 2015 reported increased prescribing of opioids and acetaminophen across nations over time [20]. A small Finnish study analyzing opioid use in 2003 and 2011 among institutionalized elderly found an increase in opioid use from $11.8 \%$ in 2003 to $22.9 \%$ in 2011 [21]. Another study from Finland investigated changes in opioid, paracetamol, and antipsychotic use among nursing home residents and similar to our study found that opioid use increased (from $11.7 \%$ in 2003 to $30.2 \%$ in 2017) and antipsychotic use decreased (from $42.7 \%$ in 2003 to $32.7 \%$ in 2017). Furthermore, they studied use of paracetamol and found that it increased from $34.3 \%$ in 2003 to $51.6 \%$ in 2017 [22]. A Norwegian study, evaluating analgesic prescribing in four different samples of nursing home residents, found an increase in opioid use from $10.9 \%$ in 2000 to $23.8 \%$ in 2011 [23]. In the general population, increased opioid prescribing has been reported in many countries [24, 25]. Thus, our findings are in line with international prescribing trends in the elderly but, surprisingly, the increase was steeper among elderly with dementia despite a higher baseline.

One may speculate about the reasons for the disproportionate increase in opioid use among elderly with dementia and possible explanations could be: 1) increased awareness of and attention given to pain in elderly with dementia; 2) disproportionate increase in painful conditions among elderly with dementia; 3 ) reflection of the general increase in opioid prescribing; and 4) use of opioids for indications other than pain.

First, pain in elderly with dementia has been the subject of more attention over the past 10-15 years, with increasing opioid use possibly a reflection of improved recognition and treatment of pain. In 2000, however, opioid use was already higher in elderly with dementia compared with elderly without and has had a steeper rise. Thus, improved recognition and treatment of pain is most likely not the only explanation. A second alternative explanation is that our study population of elderly with dementia had more pain-causing conditions. When adjusting for painful conditions and other comorbidities in our logistic regression analysis, however, elderly with dementia still had a larger increase in opioid use.

Third, opioid use has increased in the general population [24, 25], making it unsurprising that this is also the case in elderly with dementia. The increasing opioid use is primarily driven by an increase in use of transdermal formulations, which were marketed in Denmark in 1995 (fentanyl) and 2003 (buprenorphine). Previously, it was thought that pain was undertreated in elderly with dementia [26-28] which means that the increase in opioid use may be a reflection of adequate pain treatment. However, 
prevalence and treatment intensity of opioid use was already higher in 2000 in elderly with dementia compared with elderly without, with a larger increase in both prevalence and treatment intensity continuing to occur. The Danish Dementia plan from 2010 did not contain adequate guidance on palliative care including pain relief and psychosocial interventions to neuropsychiatric symptoms [29], which may be part of the explanation for the high use in 2000 and why it continued to increase. In September 2014, we published our previous study about opioid use among elderly with dementia [13], which led to a considerable amount of debate and the Minister of Health had to explain how he would handle the matter. The debate may have stopped the increase in opioid as there was no further increase after 2013. This indicates that the general increase in opioid prescribing is not the only explanation.

Fourth, the increase in opioid use occurred simultaneously with a decrease in antipsychotic use. There has been a marked decrease in antipsychotic use since 2004 due to safety warnings [6-8], public debate, and educational efforts, but behavioral symptoms still pose a considerable challenge for family and professional caregivers $[1,2]$. Naturally, a search for alternative ways to treat behavioral symptoms has occurred. Awareness of the fact that pain can lead to behavioral symptoms in elderly with dementia has grown in the past 15-20 years [30,31]. However, pain is only one of many reasons why elderly with dementia develop behavioral symptoms, which is why a thorough workup is recommended before prescribing analgesics to treat these symptoms $[32,33]$. Thus, one could speculate that physicians and caregivers are overly aware of pain as a cause of behavioral symptoms. The apparent effect of opioids on behavioral symptoms may reflect the sedative rather than the analgesic effect of opioids. As a result, another possible explanation for the disproportionate increase in opioid use in elderly with dementia is that opioids, to some extent, have replaced antipsychotics in managing behavioral symptoms, despite lack of evidence for effect of opioids [34].

An important issue is whether opioids are safe to use in elderly with dementia. Elderly with dementia have generally been excluded from clinical studies of opioids, just as a lack of knowledge exists about the clinical effect on pain and adverse events associated with opioid use in this patient group. Opioids have been associated with an increased risk of fall and fracture in the elderly [10] and mortality in patients with chronic non-cancer pain [11, 12].
In recent years, there has been increasing concern about the risk associated with opioids in general $[35,36]$, and recent guidelines recommend nonopioid therapy to treat chronic non-malignant pain $[35,37]$. Several warnings have been issued against using fentanyl patches in non-opioid-tolerant patients because of serious adverse events and deaths [38]. In a recent study of tolerability of buprenorphine in nursing home residents with advanced dementia, 52.3\% discontinued treatment due to adverse events, with sedation/somnolence being the most frequent, compared with $13.3 \%$ in the placebo group [39]. Thus, the greater increase in opioid use among elderly with dementia, is a cause for concern.

\section{Strengths and limitations}

One of the major strengths of this study was that it is based on data from the public Danish health care system, which completely covers the entire Danish population, making it possible to study real-life prescription patterns over time and eliminating problems of selection bias. The validity of registered dementia diagnoses at hospitals has previously been shown to be high [40], but most cases are registered as unspecific dementia. Dementia is generally underdiagnosed and potentially undiagnosed cases among the reference group could lead to an underestimation of differences between elderly with dementia and elderly without. Furthermore, a limitation is that information about severity of dementia, diagnosis of pain and presence/absence of behavioral symptoms is not available. The Danish National Prescription Registry records all prescriptions filled at pharmacies and the information has proven to be accurate [17]. A limitation, though, is that the exact indication is not recorded, just as there is no certainty that the patients consumed the drugs. Another limitation is that the data does not allow us to distinguish between regular and as required use, neither does is contain information about efficacy of analgesic or antipsychotics therapy. Our study is a descriptive study, which can generate hypothesis about drug use, but the design is not suited to investigate causality.

\section{Conclusion}

Use of opioids increased from 2000 to 2015, with a disproportionate steeper increase among elderly with dementia despite an already higher baseline in 2000 . The increase in opioid use in elderly with dementia was mainly due to an increase in strong opioid use, 
but particularly the use of transdermal formulations of opioids increased dramatically in elderly with dementia. Concurrently, a decrease in antipsychotic use in elderly with dementia has occurred. The parallel decrease in antipsychotics raises the issue of whether opioids, to some extent, have replaced antipsychotics in managing behavioral symptoms, despite safety concerns and lack of evidence for effect. As opioid use is on the rise in several countries, there are reasons to believe that our findings apply outside Denmark and should be cause for international concern. We recommend conducting more research to provide evidence for the benefit and risk associated with opioid use in elderly with dementia.

\section{ACKNOWLEDGMENTS}

The Danish Dementia Research Centre is supported by grants from the Danish Ministry of Health (file no. 2007-12143-112/59506 and file no. 0901110/34501).

Authors' disclosures available online (https:// www.j-alz.com/manuscript-disclosures/19-0787r1).

\section{SUPPLEMENTARY MATERIAL}

The supplementary material is available in the electronic version of this article: http://dx.pdoi.org/ 10.3233/JAD-190787.

\section{REFERENCES}

[1] Selbaek G, Engedal K, Benth JS, Bergh S (2014) The course of neuropsychiatric symptoms in nursing-home patients with dementia over a 53-month follow-up period. Int Psychogeriatr 26, 81-91.

[2] Yaffe K, Fox P, Newcomer R, Sands L, Lindquist K, Dane K, Covinsky KE (2002) Patient and caregiver characteristics and nursing home placement in patients with dementia. JAMA 287, 2090-2097.

[3] Tible OP, Riese F, Savaskan E, von Gunten A (2017) Best practice in the management of behavioural and psychological symptoms of dementia. Ther Adv Neurol Disord 10, 297-309.

[4] Gill SS, Bronskill SE, Normand SL, Anderson GM, Sykora K, Lam K, Bell CM, Lee PE, Fischer HD, Herrmann N, Gurwitz JH, Rochon PA (2007) Antipsychotic drug use and mortality in older adults with dementia. Ann Intern Med 146, 775-786.

[5] Wang PS, Schneeweiss S, Avorn J, Fischer MA, Mogun H, Solomon DH, Brookhart MA (2005) Risk of death in elderly users of conventional vs. atypical antipsychotic medications. N Engl J Med 353, 2335-2341.

[6] Danish Health and Medicines Authority (2004) Danish Health and Medicines Authority: Indskærper landets læger at udvise stor forsigtighed ved behandling med atypiske antipsykotika til ældre patienter med demens. [Danish].
[7] FDA (2008) Information for Healthcare Professionals: Conventional Antipsychotics.

[8] Banerjee S (2009) The use of antipsychotic medication for people with dementia: Time for action. A report for the Minister for Care Services.

[9] Husebo BS, Ballard C, Sandvik R, Nilsen OB, Aarsland D (2011) Efficacy of treating pain to reduce behavioural disturbances in residents of nursing homes with dementia: Cluster randomised clinical trial. BMJ 343, d4065.

[10] Daoust R, Paquet J, Moore L, Emond M, Gosselin S, Lavigne G, Choiniere M, Boulanger A, Mac-Thiong JM, Chauny JM (2018) Recent opioid use and fall-related injury among older patients with trauma. CMAJ 190, E500-E506.

[11] Hoffman EM, Watson JC, St Sauver J, Staff NP, Klein CJ (2017) Association of long-term opioid therapy with functional status, adverse outcomes, and mortality among patients with polyneuropathy. JAMA Neurol 74, 773-779.

[12] Ray WA, Chung CP, Murray KT, Hall K, Stein CM (2016) Prescription of long-acting opioids and mortality in patients with chronic noncancer pain. JAMA 315, 2415-2423.

[13] Jensen-Dahm C, Gasse C, Astrup A, Mortensen PB, Waldemar G (2015) Frequent use of opioids in patients with dementia and nursing home residents: A study of the entire elderly population of Denmark. Alzheimers Dement 11, 691699.

[14] Thygesen LC, Daasnes C, Thaulow I, Bronnum-Hansen H (2011) Introduction to Danish (nationwide) registers on health and social issues: Structure, access, legislation, and archiving. Scand J Public Health 39, 12-16.

[15] Lynge E, Sandegaard JL, Rebolj M (2011) The Danish National Patient Register. Scand J Public Health 39, 30-33.

[16] Munk-Jorgensen P, Mortensen PB (1997) The Danish Psychiatric Central Register. Dan Med Bull 44, 82-84.

[17] Kildemoes HW, Sorensen HT, Hallas J (2011) The Danish National Prescription Registry. Scand J Public Health 39, 38-41.

[18] Norgaard A, Jensen-Dahm C, Gasse C, Hansen HV, Waldemar G (2016) Time trends in antipsychotic drug use in patients with dementia: A nationwide study. J Alzheimers Dis 49, 211-220.

[19] Sundararajan V, Henderson T, Perry C, Muggivan A, Quan H, Ghali WA (2004) New ICD-10 version of the Charlson comorbidity index predicted in-hospital mortality. J Clin Epidemiol 57, 1288-1294.

[20] La Frenais FL, Bedder R, Vickerstaff V, Stone P, Sampson EL (2018) Temporal trends in analgesic use in long-term care facilities: A systematic review of international prescribing. J Am Geriatr Soc 66, 376-382.

[21] Pitkala KH, Juola AL, Hosia H, Teramura-Gronblad M, Soini H, Savikko N, Bell JS (2015) Eight-year trends in the use of opioids, other analgesics, and psychotropic medications among institutionalized older people in Finland. J Am Med Dir Assoc 16, 973-978.

[22] Roitto HM, Kautiainen H, Aalto UL, Ohman H, Laurila J, Pitkala KH (2019) Fourteen-year trends in the use of psychotropic medications, opioids, and other sedatives among institutionalized older people in Helsinki, Finland. $J$ Am Med Dir Assoc 20, 305-311.

[23] Sandvik R, Selbaek G, Kirkevold O, Aarsland D, Husebo BS (2016) Analgesic prescribing patterns in Norwegian nursing homes from 2000 to 2011: Trend analyses of four data samples. Age Ageing 45, 54-60.

[24] Guy GP Jr, Zhang K, Bohm MK, Losby J, Lewis B, Young R, Murphy LB, Dowell D (2017) Vital signs: Changes in 
opioid prescribing in the United States, 2006-2015. MMWR Morb Mortal Wkly Rep 66, 697-704.

[25] Zin CS, Chen LC, Knaggs RD (2014) Changes in trends and pattern of strong opioid prescribing in primary care. Eur $J$ Pain 18, 1343-1351.

[26] Closs SJ, Barr B, Briggs M (2004) Cognitive status and analgesic provision in nursing home residents. $\mathrm{Br} \mathrm{J} \mathrm{Gen}$ Pract 54, 919-921.

[27] Mantyselka P, Hartikainen S, Louhivuori-Laako K, Sulkava $R$ (2004) Effects of dementia on perceived daily pain in home-dwelling elderly people: A population-based study. Age Ageing 33, 496-499.

[28] Schmader KE, Hanlon JT, Fillenbaum GG, Huber M, Pieper C, Horner R (1998) Medication use patterns among demented, cognitively impaired and cognitively intact community-dwelling elderly people. Age Ageing 27, 493501.

[29] Nakanishi M, Nakashima T, Shindo Y, Miyamoto Y, Gove D, Radbruch L, van der Steen JT (2015) An evaluation of palliative care contents in national dementia strategies in reference to the European Association for Palliative Care white paper. Int Psychogeriatr 27, 1551-1561.

[30] Ballard C, Smith J, Husebo B, Aarsland D, Corbett A (2011) The role of pain treatment in managing the behavioural and psychological symptoms of dementia (BPSD). Int J Palliat Nurs 17, 420, 422, 424.

[31] Scherder E, Oosterman J, Swaab D, Herr K, Ooms M, Ribbe M, Sergeant J, Pickering G, Benedetti F (2005) Recent developments in pain in dementia. BMJ 330, 461-464.
[32] Kales HC, Gitlin LN, Lyketsos CG (2015) Assessment and management of behavioral and psychological symptoms of dementia. BMJ 350, h369.

[33] NICE National Institute for Health and Care Excellence (2018) NICE guideline: Dementia: Assessment, management and support for people living with dementia and their carers.

[34] Brown R, Howard R, Candy B, Sampson EL (2015) Opioids for agitation in dementia. Cochrane Database Syst Rev, CD009705.

[35] Dowell D, Haegerich TM, Chou R (2016) CDC guideline for prescribing opioids for chronic pain-United States, 2016. JAMA 315, 1624-1645.

[36] Okie S (2010) A flood of opioids, a rising tide of deaths. N Engl J Med 363, 1981-1985.

[37] Danish National Board of Health (2018). Opioid behandling af kronisk ikke-maligne smerter [danish]; Opioid treatment for chronic non-malignant pain.

[38] FDA (2007) A public health advisory: Safety warnings regarding use of fentanyl transdermal (skin) patches.

[39] Erdal A, Flo E, Aarsland D, Selbaek G, Ballard C, Slettebo DD, Husebo BS (2018) Tolerability of buprenorphine transdermal system in nursing home patients with advanced dementia: A randomized, placebo-controlled trial (DEP.PAIN.DEM). Clin Interv Aging 13, 935-946.

[40] Phung TK, Andersen BB, Hogh P, Kessing LV, Mortensen PB, Waldemar G (2007) Validity of dementia diagnoses in the Danish hospital registers. Dement Geriatr Cogn Disord 24, 220-228. 